\title{
Research on the Position of Both China and US to Deal with the Financial and Economic Problems Caused by COVID-19
}

\author{
Jing $\mathrm{Li}^{1, *}$ \\ ${ }^{1}$ Master of banking and finance, Monash University, Melbourne, Australia, 3000, \\ *Corresponding author. Email: jlii0253@student.monash.edu
}

\begin{abstract}
Covid-19 began in 2020 in an unexpected way as the most serious global non-traditional security shock in a century. China is the first major economy to resume growth since the outbreak, and it is at the forefront of the world in terms of epidemic prevention and control and economic recovery. However, The U.S has not fared as well in the new crown epidemic, as reflected by the fact that the U.S. economy has been grim and has become the country with the highest number of infections and deaths in the world. This study focuses on China's financial and economic response to the coronavirus are superior to those of the United States in the current epidemic situation.

This paper uses research methods such as observation, literature research and information research methods. The main object of the study is the different measures taken by China and the United States to save the economy and life from the damage caused by the epidemic. In the current epidemic situation, China seems to have an advantage over the United States in dealing with the financial and economic aspects of the coronavirus, but the United States has an irreplaceable power as the largest economy and the most productive country in the world. The main tools used for the study were excel tabulation, word editor and google search. The data for the study were mainly obtained from the official website of the China Bureau of Statistics and the official website of statistics in the United States.

Research pointed out that China's advantages are multifaceted. First, China's central government is better able than the US federal government to implement a unified policy while unlike bipartisan struggle in the United States, it is more efficient to insist on one-party leadership. Moreover, China attaches great importance to cooperation, especially solidarity with Southeast Asia, and ideological management. During the epidemic, Trump focused more on economic development of the United States to support his re-election and neglected the prevention of the epidemic. However, mass vaccination brought about by new president government has also created a new situation in the United States. As the world's largest economy and most productive country, America has a power that cannot be underestimated. Although China has achieved relatively good results during the epidemic, in the context of a full-scale economic recession, China should be more mindful of the crisis even in times of peace. Significantly, China needs to learn from the lessons, as historical coronavirus first emerged in China, meanwhile, needs to learn from advanced technologies, where U.S. vaccine research has a relative advantage. By strengthening the development of private enterprises and avoiding market failure effects caused by the government, the progress of China's socialist economic system can be promoted.
\end{abstract}

Keywords: Covid-19, Economy, Comparison, China, the United States 


\section{INTRODUCTION}

\subsection{Background}

Table 1 Total global coronavirus episodes by country

Total global coronavirus episodes by country, as of June 2021 ('000)

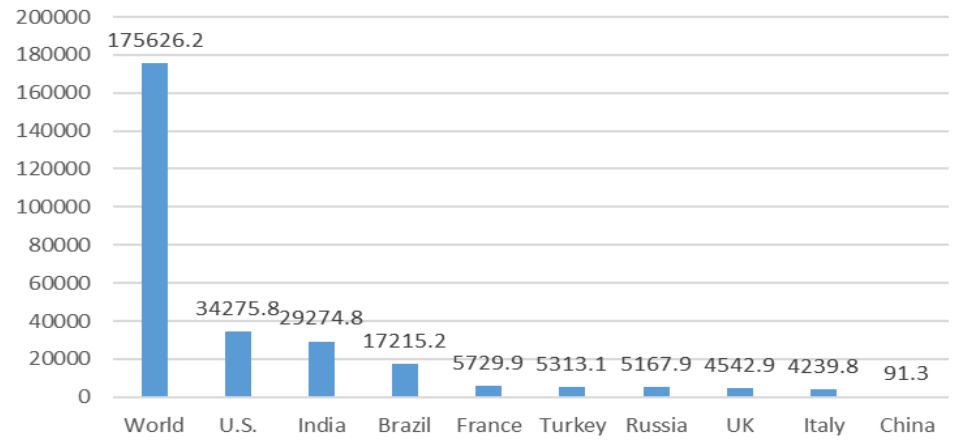

Retrieved from: https://www.statista.com/

Table 2 Total coronavirus episodes by states in US

Total coronavirus episodes by state in the United

States as of June 2021 (in units)

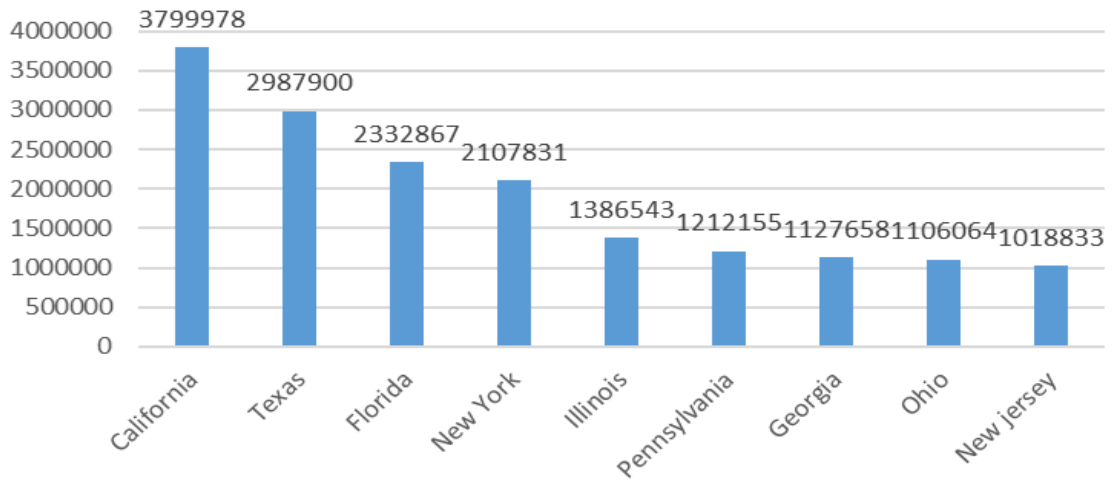

Retrieved from: https://www.statista.com/

Table 3 Total number of coronavirus by province in China

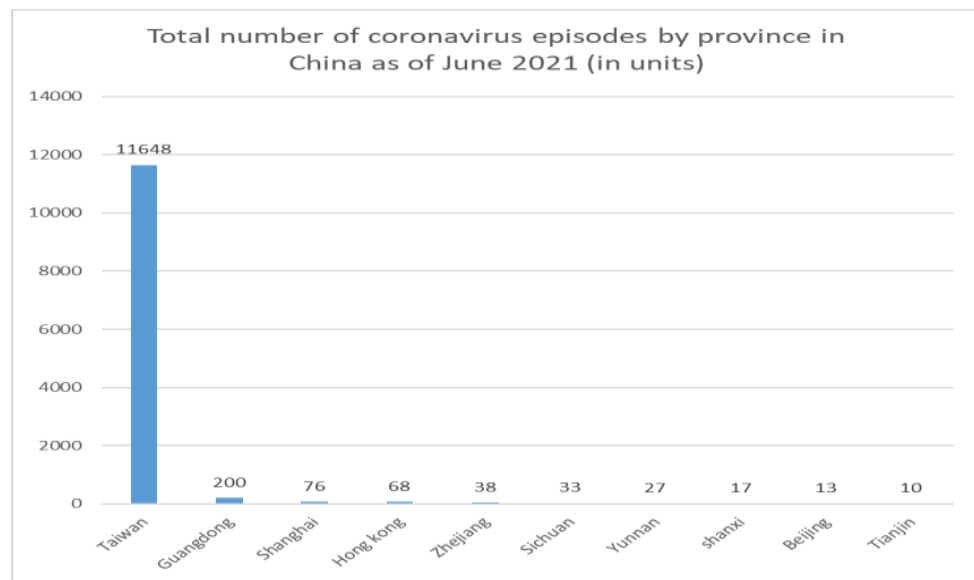

Retrieved from: http://www.stats.gov.cn/ 
The Covid-19 spread rapidly around the world, triggering a global economic recession. It was a classic "black swan" event that was completely unexpected. The epidemic has a relatively large negative impact on the economic growth of the United States, and a relatively small negative impact on the economic growth of China[1].

Table 4 Comparison of Unemployment rates between the US and China

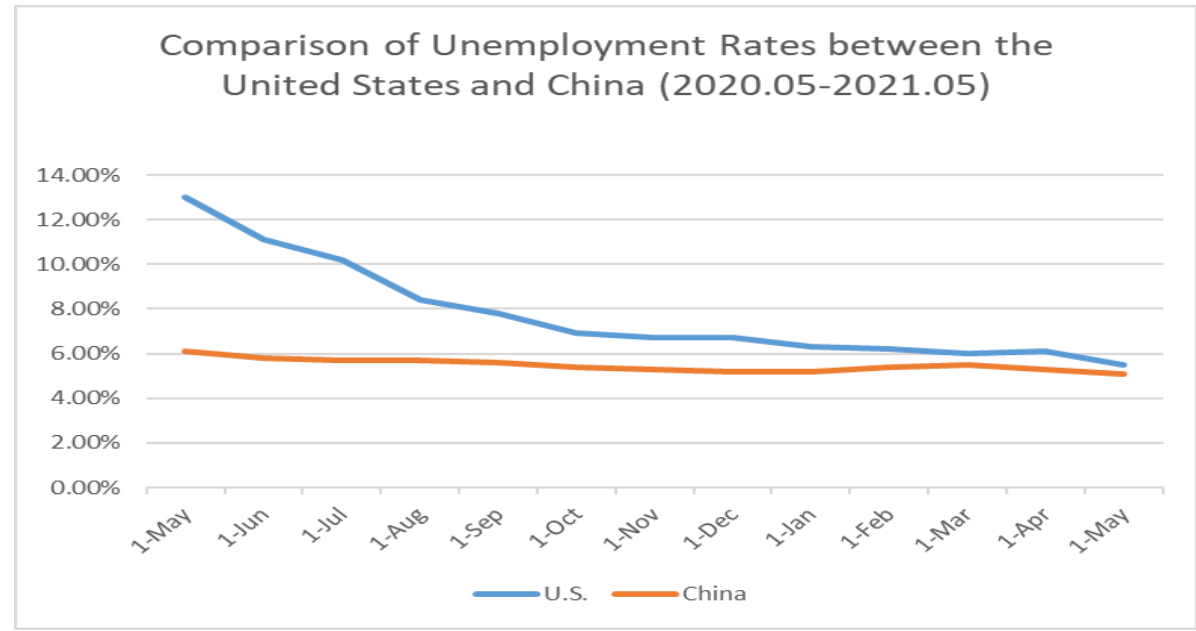

Retrieved from: https://www.statista.com/

According to the analysis by the Bureau of Economic Analysis of the US Department of Commerce, the US GDP in the first and second quarters of 2020 has decreased by $-5 \%$ and $-32.9 \%$ respectively, which is the steepest decline since the US government started tracking the data in 1947, and unemployment rates also increased significantly during the epidemic. However, in China, GDP recovered rapidly and unemployment remained at a stable level[2].

\subsection{Research Aim}

This paper will discuss China's advantages compared with the United States in dealing with the Covid-19 issue, and analyze the new situation brought by the new president of the United States and the economic problems that China needs to solve.

\section{ANALYSIS}

With the world still shrouded in the negative sentiment of COVID-19 and the economy being severely stagnating, China has gained a strategic priority and has greater advantages in economic recovery and rebound[3]. At the same time, novel coronavirus is still spreading throughout the United States, causing many impacts on social order and economic life. It shows that China has certain advantages in coping with the economic problems caused by the epidemic.

\subsection{On the issue of Central Government power}

Generally speaking, China's basic economic system is able to actively and effectively respond to public emergencies because of its essential characteristics, that is, it always adheres to the leadership of the Party, which enables China to quickly unite the whole Party and the country. However, the U.S. government does not have an overall coordinated plan to respond to the epidemic.

Firstly, the federal government's epidemic prevention efforts have been constrained by the system. Some of the specific matters in the epidemic are determined by the state governments. The outbreak of the Covid-19 required the federal government to use massive manpower and material resources to combat the epidemic. However, the powers of the federal government are limited by the federal constitution and are not granted arbitrary power in the case of a public health emergency.

Furthermore, Republicans Democrats have been divided over anti-epidemic measures, leading to ineffective coordination of prevention and control of the epidemic. A study by a professor of political science and economics at Binghamton University found that throughout the COVID-19 pandemic, there were partisan differences in the government's appropriate response to the public health crisis[4]. For instance, on the issue of whether people should wear face masks, the Democratic Party has issued regulations requiring people to wear face masks when they go out. Violators face fines or up to six months in jail. However, the Republican Party later announced that local authorities were banned from forcing residents to wear masks in public places, and proposed that whether or not to wear masks was entirely up to the people.

In addition, the election also led to contradictions. In order to restart the economy as soon as possible, obtain support from voters, and fight for re-election, Trump opposes measures to prevent and control the epidemic 
that hinders economic development, such as restricting population flow[5]. However, from another aspect, the rapid spread of the novel coronavirus can deal a heavy blow to the US economy, which will be the biggest capital against Trump's re-election.

\subsection{On the issue of cooperation}

As the Covid-19 epidemic has emerged in numerous countries, it is necessary for countries to strengthen communication and cooperation in the area of public health security. While doing an excellent job in the prevention and control of the epidemic in its own country, China will provide support to other countries within its capacity. For example, China has provided testing reagents to Pakistan, Japan, and the African Union through multiple channels, shared diagnosis and treatment plans with many countries, and sent a team of volunteer experts to Iran. China has supplied 15.755 million kits in total, despite the current global shortage of kits[6].

On the contrary, at the critical moment of global epidemic prevention and control, America violated its own international responsibilities and obligations by withdrawing US\$400 million in membership dues and withdrawing from the World Health Organization, which aroused strong dissatisfaction and indignation from the international community[8].

\subsection{On the issue of ideology}

In the early stage of the epidemic, China implemented "closure of cities" management measures in some cities in Hubei, Zhejiang, Henan ,and other provinces. Most cities have also taken measures such as quarantine at home and extending the Spring Festival holiday to avoid large-scale population movement and population, effectively cutting off the transmission chain of the epidemic[7].

However, there was serious resistance to quarantine measures in the United States. On the one hand, some religious people in the United States do not have a clear understanding of the possible personal harm caused by Covid-19 and have no awareness of prevention. On the other hand, some Americans believe in liberal values, which place individual freedom above everything else and oppose excessive government intervention in personal life. Therefore, some Americans find practices such as home isolation and closing business premises psychologically unacceptable[8].

\subsection{On the issue of medical insurance}

The National Medical Insurance Administration of China and the Ministry of Finance clearly put forward the "two guarantees" requirements of " ensuring that patients will be affected by the cost of medical treatment, and that medical institutions will not be affected by the payment policies of treatment". During the epidemic, medical insurance policies are improved and adjusted in a timely manner, and the government will provide partial subsidies to reduce the burden on individuals and alleviate the worries of patients. In order to treat patients with COVID-19, the reimbursement rate of medical insurance in China is as high as $66.6 \%$.

However, the United States is still a developed country without universal health insurance, and currently has one of the highest per capita investments in health care in the world. In the United States, in addition to testing costs for new coronary pneumonia, all treatment costs are borne by patients themselves[9]. Many Americans, especially some of the lower-income groups and those who enter the United States undocumented, do not have commercial health insurance. As a result, patients are not treated for fear of being unable to afford the cost, which in turn leads to the further spread of the virus[10].

\section{A NEW TURN FOR THE NEW PRESIDENT OF THE UNITED STATES}

Many of the problems and errors in the United States' fight against the epidemic belie the overall image of the United States as the world's most powerful, technologically advanced, and medically advanced nation. This is due in large part to the Trump administration's incompetence in fighting the epidemic. They have not only shirked responsibilities internationally, but also repeatedly made groundless accusations against China and the World Health Organization[11]. At the same time, a series of epidemic prevention and control measures proposed by the expert group were abandoned.

The Biden administration, however, changed the mindset of the Trump administration, which was the eagerness to achieve success and tempting to "success in a single battle" in a short period of time[12]. Instead, America has strengthened cooperation with allies and emphasized strengthening its own competitiveness. First, the Biden administration tried to reassert the US's global leadership position. Biden stressed that the United States must lead by example by renewing its engagement with the international community and seeking to restore its former international role. He also reversed the Trump administration's frequent international "retirement" practices by announcing the United States' return to climate change and the Paris Agreement, and the intention to rejoin the World Health Organization and the UN Human Rights Council. At the same time, Biden will update major spending programs allowed by Congress, such as providing emergency paid leave. He will continue to take strong macroeconomic stimulus measures until income and employment return to pre-pandemic levels. In the meantime, Biden plans to 
drastically reduce the number of Americans without health insurance. Most importantly, Biden will implement a federal program to combat the coronavirus under the professional guidance of scientists and health professionals. This includes the development of safe and effective vaccines and enhancing the public health capabilities of the United States to respond to future crises. For example, in April 2020, the White House announced that it would allocate US $\$ 1.7$ billion to vaccinate people against the coronavirus variants. Currently, with the large-scale vaccination in the United States, the American people have seen the trend of epidemic control and the hope of economic recovery. After all, the United States is still the most productive country in the world, not only leading the world in terms of manufactured products but also the largest exporter of goods and services[13].

\section{DISADVANTAGES OF THE CHINESE SYSTEM}

Although China has shown some advantages in this war against the epidemic, staying many problems that need to be solved.

\subsection{Learning from the lessons of the coronavirus}

The first manifestations of both the new coronavirus (or SARS) in China stem from the excessive political considerations and hesitation in responding to challenges to authority. Transparency does not bring panic, only the absence of truth is the source of public panic. 18 years ago SARS left China with a lesson that the outbreak has been confirmed at a tragic cost again. Compared to China, U.S. media enjoys more freedom of expression.In the U.S., news of the epidemic may have been released earlier and the disease may have been brought under control sooner.

\subsection{Learning from U.S. efforts in vaccine development and promotion}

Table 5 Covid - 19 vaccination measures by state in the US

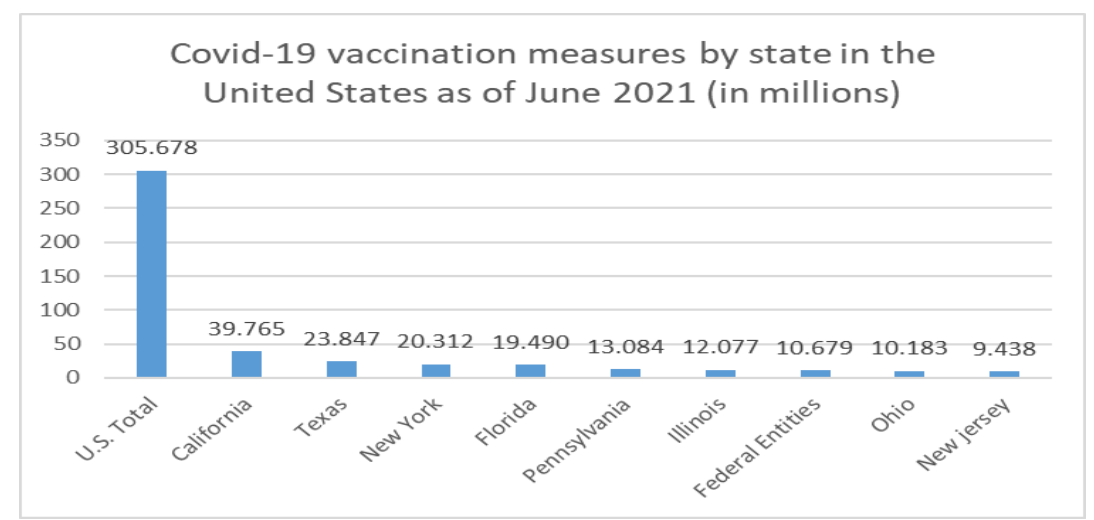

Retrieved from: https://www.statista.com/

Table 6 Number of Covid-19 vaccination measures by province in China

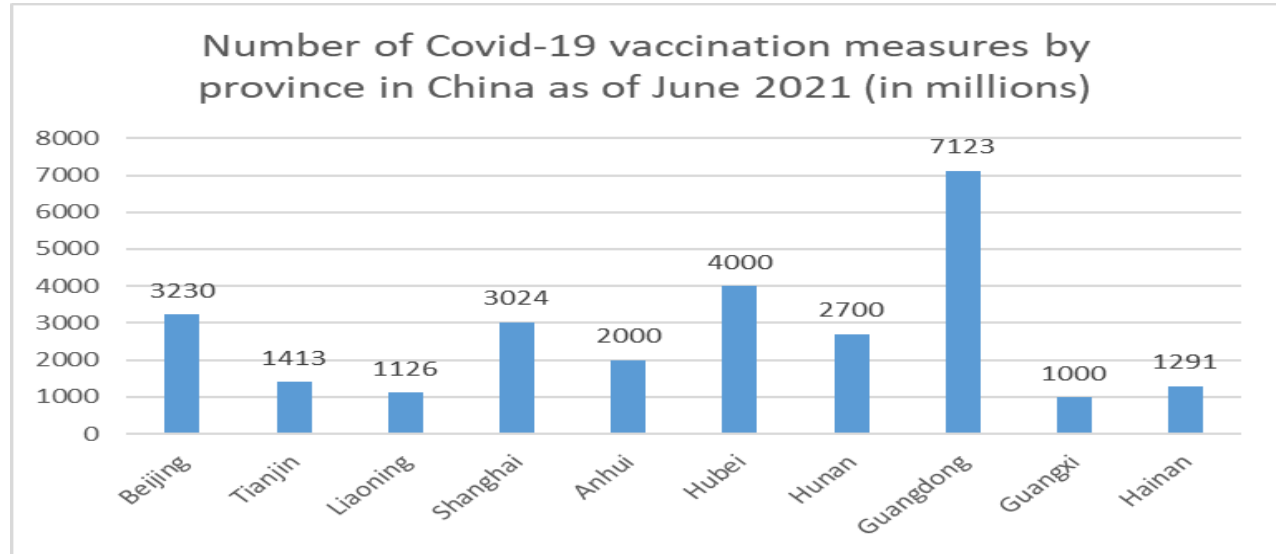

Retrieved from: http://www.stats.gov.cn/ 
Compared with the United States, China has a shorter history of vaccine specialization. In terms of the contribution of vaccine candidates, the U.S. has 57 of the 166 vaccine candidates announced by WHO, accounting for $34 \%$, while in terms of the national distribution of subjects, the U.S. has the highest participation of subjects such as companies, universities and research institutions. In early 2020, the U.S. vaccine was the first to start clinical trials with strong funding from the National Institutes of Health, becoming the first new crown candidate vaccine to start human clinical trials in the world. According to data monitored by the University of Oxford, approximately 1.9 billion

doses of vaccines have been administered worldwide. In the first months after the vaccine was introduced, approximately $52 \%$ of the U.S. population has received at least one dose of the vaccine, and $42 \%$ have been fully vaccinated. However, China is now on an "accelerated run" of new vaccinations. In early June, China has accumulated more than 800 million doses.

\subsection{Strengthen the management and \\ transformation of the economic system}

Table 7 Top 10 countries with the largest gross domestic product

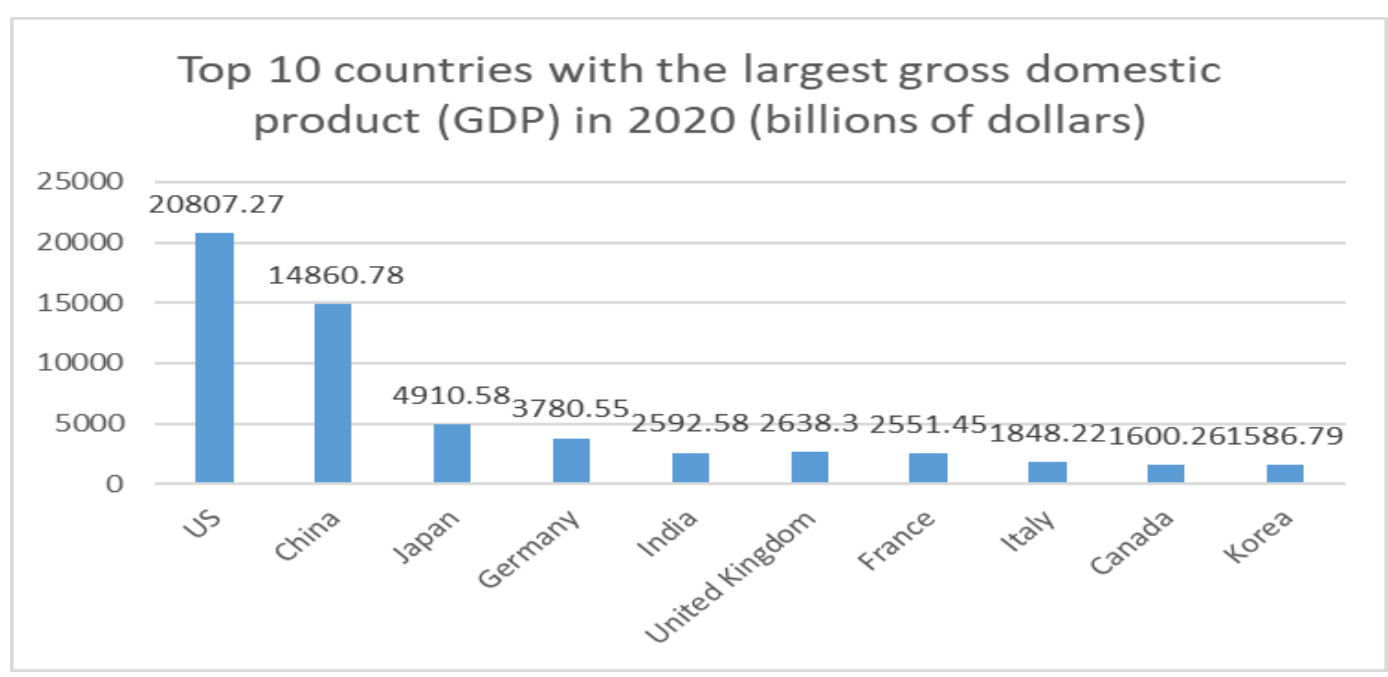

Retrieved from: https://www.statista.com/

In nominal dollar terms, the size of the US economy is almost twice that of China. Although the impact of the epidemic on China is limited, in the context of the global economy gradually entering a recession, Chinese residents should remain vigilant in times of peace and pay attention to the management of the economic system. Firstly, supporting the development of private enterprises. As the mainstay of China's economy, state-owned enterprises occupy a large number of high-quality social resources. If they cannot be transformed into modern enterprises as soon as possible, they will cause a great drag on the transformation and reform of China's economy. Many Chinese private enterprises have performed quite well during the epidemic, which was embodied in the research and development of anti-epidemic drugs, production of protective clothing, and material donations[14]. Secondly, avoiding the chain reaction of market failure. The Chinese government has long played a crucial role in economic growth, but this mode of economic development requires high levels of government decision-making and regulation. Once the government makes adverse decisions that reduce economic efficiency, the government will become ineffective. It will have a direct negative impact on China's financial industry. The government directly regulates the deposit and loan interest rates, and the interest rates cannot fully reflect the deposit and loan risks in the market, which makes the market unable to achieve complete competition[15].

\section{CONCLUSION}

China took the lead in successfully preventing and controlling the epidemic and stabilizing the economic situation. The research of this paper found that China's advantage over the United States in the process of fighting against the epidemic and defending the economy lies in the fact that China always adheres to the leadership of the Party and there is no campaign problem. It focuses more on cooperation with other countries and strict domestic control of ideology. The spread of the epidemic has coincided with the US general election. A new President, Joe Biden, reversed the unfavorable situation of the former president, bringing in vaccines, regaining the confidence of the American people and gradually restoring the US economy. Finally, in the case of the overall economic recession, China should summarize historical lessons to learn advanced technology, furthermore, actively adjust its economic system to cope with the global economic 
recession, by strengthening the development of private enterprises and avoiding the market failure effect caused by the government.

\section{AUTHORS' CONTRIBUTIONS}

This paper is independently accomplished by the author.

\section{ACKNOWLEDGEMENTS}

Firstly, I sincere thanks my respected mentor Professor Armstrong-Taylor. Prof.Armstrong-Taylor's profound knowledge, rigorous academic spirit, and keen insight have provided key inspiration and help for the topic selection and writing of my thesis.

Furthermore, I sincere thanks the academic research project exploring the financial crisis, which made me deeply aware of the relationship between the new crown epidemic and the economy. During the research, I deeply felt the lack of knowledge structure, and the long road of learning slowly has just started.

\section{REFERENCES}

[1] OECD. OECD Interim Economic Assessment Coronavirus: The World Economy at Risk. 2 March 2020. https://www.oecd.org/berlin/publikationen/InterimEconomic-Assessment-2-March-2020.

[2] Interpretation of the first quarter economic data: better than expected, the annual economic growth target forecast 2.5-3\%, Institute of World Economics and Politics, Chinese Academy of Social Sciences, 2020, http://www.iwep.org.cn/Xscg/Xscg_sp/202004/t202 00424_5118474.shtml

[3] Wang, Qiang, \& Zhang, Fuyu. (2021). What does China's economic recovery after COVID-19 pandemic mean for the economic growth and energy consumption of other countries? Journal of Cleaner Production, 295, 126265-126265. https://doi.org/10.1016/j.jclepro.2021.126265

[4] Zhang Wei. US Congressman: I would rather die more Americans to save the economy, and the two evils should be the lesser [N/OL]. Surging news. 2020-04-17.

https//www.thepaper.cn/newsDetail_forward_7015 047.

[5] Du Jifeng. US Epidemic Prevention and Control and US National Conditions. Northeast Asian Journal: Epidemic Prevention and Control and National Governance, Issue 1, 2021-1
[6] Ren, Xuefei. (2020). Pandemic and lockdown: a territorial approach to COVID-19 in China, Italy and the United States. Eurasian Geography and Economics, 61(4-5), 423-434. https://doi.org/10.1080/15387216.2020.1762103

[7] Lin, Justin Yifu. (2020). China's economic outlook against the backdrop of the COVID-19 pandemic and US-China tensions. Journal of Chinese Economic and Business Studies, 18(4), 327-331. https://doi.org/10.1080/14765284.2020.1854024

[8] Shehzad, Khurram, Xiaoxing, Liu, Bilgili, Faik, \& Koçak, Emrah. (2021). COVID-19 and Spillover Effect of Global Economic Crisis on the United States' Financial Stability. Frontiers in Psychology, 12, 632175-632175. https://doi.org/10.3389/fpsyg.2021.632175

[9] Wang Xiaohui. $82 \%$ of Americans do not have basic medical insurance to pay, and the cost of treatment for new coronary pneumonia must be paid at their own expense [N/OL]. China Times, 2020-03-20. https://www.chinatimes.net.cn//article/95386. html.

[10] U.S. medical treatment needs "a little more socialism" [EB/OL]. (2020-05-26). http: //m. cankaoxiaoxi. com/column/20200526/2411453.shtml.

[11] Keith Johnson and Robbie Gramer,"The Great Decoupling,’Foreign Policy,May 14,2020.

[12] U.S. Congress,“H. R. 6074,"available at: https: / / congress.gov / bill /116th-congress / house-bill /6074 /, 2020. 4. 19.

[13] Jim Chappelow, “American Recovery and Reinvestment Act,"available at: https: / / www.investopedia.com / terms /a / american-recovery-and-reinvestment-act.asp, 2020. 5. 12 .

[14] Li Xiao, Chen Yu: "The World Economy Under the Impact of the Epidemic and China's Countermeasures", "Northeast Asia Forum", Issue 3, 2020 .

[15] Ding Chun: "The epidemic has exposed the structural deficit of the global economic governance system", "National Governance", Issue 3,2020 . 